\title{
SLIP OF THE TONGUE IN BARACK OBAMA INTERVIEW AT THE AXE FILE
}

\author{
Siti Zulaihah ${ }^{1}$, Rohmani Nur Indah ${ }^{2}$ \\ 1,2 Universitas Islam Negeri Maulana Malik Ibrahim Malang \\ ${ }^{1}$ sitizulaihah122@gmail.com, ${ }^{2}$ indah@bsi.uin-malang.ac.id
}

\begin{abstract}
This study examines the type of slip of the tongue in Barack Obama's interview at The Axe Files. It also analyzes the possible factors causing the error in speech production in the context of political discourse. It used Fromkin's and Clark's theories to investigate the audio data on The Axe File episode 108 and 288 published in 2016 and 2018. The result shows that Obama employed anticipation, perseveration, transposition, substitution, blend, and haplologies. The dominant type produced in the interview is substitution. In addition, the factors influencing slip production are cognitive difficulty, situational anxiety, and social factors. These findings can be a reference for EFL teachers to show the various type of speech error produced in political discourses by native speakers. Further researchers are expected to use other relevant theories to classify a slip of the tongue in several other contexts.
\end{abstract}

Keywords: Psycholinguistics, Slip of Tongue, Speech Error

\section{INTRODUCTION}

Slip of the tongue is one form of speech errors that occur when are regarded mostly as errors of articulation. According to Dell (1986) as cited in Altiparmak and Karuoglu (2014), slip of the tongue is an accidental, habitual divergence from a speaking plan. In other words, it occurs as unconscious deviations from the objective form that the speaker wanted to produce (Golrick and Daland, 2016). The speaker wants to produce many words, phrases, or sentences, but an error happened in the planning process so that production is not following the plan (Jaeger, 2005). Whereas according to Fromkin (2006) as cited in Fitriana (2018), the slip of the tongue has resulted from a depressed mind; it is expressed by inevitable mistakes made by the speaker. Poulisse (1999) establishes two criteria to apply the assumption about the slip of the tongue; there are: first is there must be word an error. The second is the speaker must be able to correct the word error. In this case, the first criteria are helping a researcher to exclude the other form of speech error, disorder, and disfluencies, such as false start, inappropriate lexical item, or stuttering. Therefore this criteria is essential to identify of slip of the tongue. Furthermore, the second criteria also assist in excluding several of habitual errors that repeatedly occur in the speaker speech without any correction.

According to Zhu and Liu (2018), there are two main causes of speech errors; the first caused by psychological factors and the second caused by physiological factors. One of the psychological factors is dominated by the consequences of the oppressed mind displayed by certain errors, while the physiological factor that can cause speech error are included gender, age, and physical conditions. In addition, the slip of the tongue can be caused by several different factors. 
Dell and Reich (1986) summarize some factors affecting the frequency of the slip of the tongue, among others are syllable stress, distance of the elements, item and context similarity, phoneme combination, lexical expectation, semantic editing, and speaking rate. The stress effect more often occurs on the slips, which involving stressed syllables more than slips involving unstress syllables (Boomer and Laver, 1968). The distance effect includes the communication of two units in the system of speech production. The item similarity in terms of phonemes also become most possibility effects causing slip of the tongue. The context similarity in which identical to the previous phonemes are most possibility occurring slip of the tongue (MacKay, 1970). The phoneme combinations frequency may also result in slip of the tongue. The lexical expectations of the speaker who looked forward to expressing nonsense syllables are regarded as another trigger of slips. The semantic editing means the potential slip of the tongue, producing semantically inappropriate text (Motley and Baars 1976). As the last effect is the speaking rate, if the speaker speaks faster, it possibility occurring slip of the tongue on his speech (MacKay, 1970).

Concerning the slip of the tongue, studies show various results. Altiparmak \& Karuoglu (2014) confirmed that the older, the more opportunities to produce tongue slips in spoken language. Moreover, the educational background also affects one's tongue slip. Besides, educated people do not produce tongue slips as do uneducated people. Detrianto (2017), found that nearly all types of slip of the tongue occurred in the classroom presentation of international students. Thai and Libyan students produce additions, anticipations, changes, misderivation/shifts, mixtures/haplology, preservation, and deletions. Besides, the most influencing factor was the cognitive difficulty. Another research, Fitriana (2018), showed that slip of the tongue occurs in a formal interview of some Indonesian state official. The dominant slip of the tongue, in this case, are semantic errors, and perseveration errors as part of assembling errors.

According to the previous studies, there is not enough explanation about slips of the tongue that happened in the open interview, especially in political discourse. Accordingly, this study investigates slips of the tongue of the famous figures such as Barack Obama whose native language is English. The context of live interview chosen because it involves face to face communication and the conversation ran naturally.

The present study aims to analyze the slip of the tongue on Barack Obama's interview. The researcher selects slip of the tongue because the slip of the tongue is a phenomenon that can occur to anyone, it can occur in small children, adults, or parents, people who have high positions or ordinary people. The Axe File as selected as the object of the study since this podcast revealed the interview with the politicians figure and the 44th President of the United States conversing prominent issues.

This study uses psycholinguistics as an approach. As a study of mental processes in the use of language (Harley, 2001), psycholinguistics uncovers the relation between language and mind (Aitchison, 2008). In slip of the tongue phenomenon, the process of speech production is influenced by the psychological factors, such as the emotional state as a sense of enthusiasm, anxiety, concern, feeling rushed, feeling nervous, even angry (Harley, 2006). The focus of this study is exploring Barack Obama's interview on its types of slip of the tongue that found and the possible factors causing the production of slip of the tongue.

This study is expected to be useful practically and theoretically in speech productions, especially the slip of the tongue. Theoretically, this study is expected to develop the 
implementation of the theory about the phenomenon of slip of the tongue, especially on revealing the topic in political discourse. Practically, this study is thought to present a comprehensible description of the types and the factor influence of slip of the tongue in Barack Obama's interview, besides that this research useful for those interested in psycholinguistic research to encompass the phenomenon of slip of the tongue.

\section{METHOD}

The method of this research is descriptive qualitative. In this research, the researcher used Barack Obama's interview as the object posted on YouTube. The researcher takes two episodes available online; episode 108 published on 26 December 2016 and episode 258 published on 20 November 2018. The duration of each interview is an hour.

The data were collected in several steps. The first is listening to the audio to get a deep understanding of the utterances. The next step is comparing the utterance in the interviews between the audio and the text of the transcript obtained from the official website. The third step is encoding the data source; this step makes it easier for the process of data entry. The last step is data reduction and display.

This study used the theory of slips of tongue (Gleason and Ratner, 1998) theory and the framework proposed by Well, Hockett, and Fromkin as cited in Dell and Reich (1986). It covers seven types of slip tongue; those are anticipation, transposition, substitutions, perseveration, blends, counter blends, hapiologies. In addition, it also used Clark and Clark's theory as cited in Detrianto (2017) about the factors influence of the slip of the tongue; there are social factors, cognitive difficulty, and situational anxiety.

\section{RESULTS AND DISCUSSION}

\section{Results}

The interview audio of episode 108 discusses the history of Obama's life, starting from his teens to how he became president, besides Obama's struggle to overcome partisan politics in Washington. Obama told about his success was from not only his struggle but also the support of the people. In the beginning, Barack Obama told about his experience smoothly and clearly, but in the middle, he repairs his utterance. You know, it didn't always manifest itself in the day to day grind of governing, but the truth is it's -- it never died out (datum 1). In this case, the speaker preserves the appearance of a sound; then the sound is pronounced instead of the sound that should be. Therefore it includes preservation. It also involves silent pause, as he hesitates to choose the word to utter, which characterizes as cognitive difficulty in finding a more suitable expression.

Barack Obama tells David and also audiences about his coming to Los Angeles for the Democratic meeting. In the beginning, his expression is smooth, but then he was not right in saying a word, then he repairs his utterance. $I$-- I've -- I'm proud that I have tried to conduct myself in the office to do what I think is right rather than what is popular (datum 2). Obama should say the word "I'm" but the result of his uttered is "I've", he replaces the syllable "am" to be the syllable "ve". However, after realizing it, he corrects the wrong word in the pronunciation. In this case, slip of the tongue occurs in his pronunciation, he did false start and anticipation. In this case, his being excited to tell the audience about the Democratic meeting, affected the utterance so that the slip is caused by a social factor. 
Barack Obama discusses his overcoming of a difference. At minute 33.35 on the audio data, he hesitated and resulted in a slip of the tongue. Yeah, but -- but I-I...I've I always viewed that as an aspirational speech, not a perfect description of what is but a description of our best selves and who we might be (datum 3). The speaker repeated the first words. The repetition shows how Obama took longer time to produce the first word of the first word for the abstract topic; therefore, it refers to cognitive difficulty.

In another utterance, Barack Obama talks about his activities after he resigned from the political world. He was preoccupied with writing his first book, besides he made an organization which aimed to build the next generation, organizers, journalists, politicians. However, in his explanation, there was hesitation in his speech. So so you just have to -- you have to get back (datum 4). He requires to skip part of the object pronounce. In the first utterance, the speaker utters the letter of "just", furthermore in the next sentence of the speaker skip this word. In this case, the speaker omitting the word; therefore, it includes one the type of slip of the tongue called haplologies. In this situation, he spoke carefully to avoid wrong explanation caused by situational anxiety.

At the beginning of the sentence, Barack Obama speaks carefully; it causes occurring of slip of the tongue in his pronounce. They're -- they haven't quite gotten to prime age (datum 5). He wanted to say "they haven't" but the result of his uttered is "they're", he replaces the word "have not" to be the word "are". However, after realizing it, he corrects the wrong word. In this situation, he spoke carefully to avoid wrong explanation caused by situational anxiety.

The second data is the interview audio of the Axe File episode 288 concerning the life of the Obama family in the Hyde Park community. Obama told about how his family sacrificed a lot for his political career, his biggest regret from his presidency, racial politics in America, increased political polarization, and other topics. When Obama responds to David Axelrod's statement that why America is a bluer and redder today than ever and is at the core of some of that, he replaced a word with another. It is - it has always been the fault line (datum 6). $\mathrm{He}$ corrects the wrong word by changing the auxiliary. Therefore this type of a slip of the tongue includes substitutions type. In responding Axelrod, he is like thinking what the sentences to say to David; therefore, social factor triggered the occurring of the slip of the tongue.

When Barack Obama answered the question on what he knows about president Trump, which is about what he will face and how he should be, he replaced a word with another as a slip of the tongue. When you don't have -- when you have at least one party (datum 7). The speaker corrects the wrong word with the right word. Therefore the type of this slip of the tongue called substitution. It seemed that he did not expect the kind of the question so that it resulted in hesitation caused by situational anxiety.

David Axelrod asked about moderate Republicans, and Obama answered the questions very quickly and simultaneously so that he was a little hasty to answer. Well they -- but they - (datum 8). Obama used interjection well and then substitute with the word "but" to be the word "well". In this case, Barack Obama is such in pressure, because when he began to talk at that time, David also talks, so Obama answered the questions very quickly. Therefore the slip results from social factor.

Axelrod asked Obama about the affordable care act. In his answer, Obama stated that he hoped that it would come a little earlier, which would be very helpful in 2014. When Obama noted about it, he hesitated to cause him to say the word in to be on accidentally. It would have been helpful on -- in -- in -- in 2014 (datum 9). In this case, slip of the tongue occurs in his articulation, because the speaker replaces the origin unit to utter. Therefore it includes transposition type. 
He spoke after some silent pause and resulted in an unintentional error caused by a cognitive difficulty.

Regarding affordable care, Barack Obama states that the United States is unique among developed countries in the world in not providing universal health services. In saying that, Obama unintentionally produced an error as he put the word has, which should be is. Because despite the fact that the United States has -- is unique (datum 10). As the speaker changes the auxiliary, this type of a slip of the tongue includes substitutions type. The speaker hesitates to choose the word to utter, showing a cognitive difficulty resulting in unintentional error.

When Obama and David are still discussing affordable care, Obama unintentionally put the word but which should be and. But -- and people tended (datum 11). In this case, the slip of the tongue occurs in his pronunciation; then the speaker changed the auxiliary. Therefore this type of a slip of the tongue includes substitutions type. The trigger is similar to the previous utterance that is a cognitive difficulty.

Obama tells about when he and Michelle are campaigning in a rural area. He repeated his word, he mentioned "we" in the first sentence, but when he confirmed in the second sentence, he skips the word "we". When we were - when were campaigning (datum 12). From this utterance, the speaker requires to skip part of the target utterance. In the first utterance, the speaker utters the letter of "we", furthermore in the next sentence of the speaker skip these word. In this case, the speaker skipping the word of "we" therefore it includes one the type of a slip of the tongue called haplologies resulted from cognitive difficulty.

\section{Discussion}

According to Dell (1986) as cited in Altiparmak and Karuoglu (2014), a slip of the tongue is one form of speech error. This error occurred because the speaker unintended said the error word. Therefore the word that spoken by the speaker is not the same with the planned word. Based on this definition, the phenomenon of a slip of the tongue also occurred in Barack Obama in an interview. In the Axe File interview Barack Obama accidentally said an error word, he expresses the word are not suitable with the word planned. This case will be discussed in this section, which shows the findings and the related theory of the slip of the tongue that occurred in Barack Obama's interview at the Axe file.

In the case of the exploration on the slips of the tongue's types produced by Barack Obama, the researcher applies the theory proposed by Fromkin (1971) as cited in Dell and Reich (1986). The basic types offered are seven:

The first type is anticipation. According to Fromkin (1971), anticipation is the stream of a unit of speech that appears as too early; this is perhaps replacing the unit that should appear. Based on the theory, the researcher found that anticipations occur in this study. The finding of this study showed anticipation type occurs in this study because Barack Obama anticipates the emergence of a sound. The sound is pronounced instead of the sound that should be an error occurs in the initial sound. It happened in the second datum, Obama should say the word "I'm" but the result of his uttered is "I've", he replace the syllable "am" to be the syllable "ve" (datum 2). However, after realizing those error, Barack Obama corrects the wrong word to be the right. This type of a slip of the tongue occurred on the utterances of Barack Obama it causes when he tells about his stories or answering the question from David, at the beginning Barack Obama said about his experience smoothly and clearly, but in the middle, he spoke there was some silent pause. 
The second type is the perseverations. In the finding of this study shown there is one datum which classified as perseverations type. The perseverations type appeared in this research because Barack Obama uttered the unit; after that, he repeated this unit to change the actual unit that occurs or the unit to utter. This type occurs in the datum 5, in which Barack Obama wants to speak "they haven't" but the result of his uttered is "they're", he replaces the word "have not" to be the word "are" (datum 5). As we know from the data slip of the tongue occurs in his pronunciation, because Barack Obama repeated the word "they" in his utterance, then he replaced the correct unit that should be "they haven't". The perseveration that occurred in the utterances of Barack Obama in this research. It is appropriate with thoughts about perseveration by Fromkin (1971). Perseveration is the unit occurred and repeated the unit to change the actual unit that happens or the unit to utter. Besides, the perseverations are sometimes referred to the repetition of the word, which the opposite of the anticipations type. If in the anticipation type, the word error occurring at the beginning of a syllable, while an error in the perseverations occurs in the wed of the syllable.

The third type is the transpositions. The finding of this study shown there is one datum which classified as transpositions type. The transpositions type occurs in this research because of the error case of the replacement of two units that should occur in the appropriate stream. In other word, transpositions type is one form of this error results from move words or sounds from one position to another position. This type occurs in the tenth data of this research which Barack Obama wants to say the word "in 2014" but the result of his uttered is "on 2014", in this case, Barack Obama replaces the word "in" to be the word "on" (10 data). As we know that the error occurred in this data because Barack Obama exchanges the position of the later of $/ \mathrm{i} /$ to be the later of $/ \mathrm{o} /$. The replacement of the sound, in this case, has a consequence on the error of the prepositions of the time. Which "on" is used to describe the time in the date and name of the day, however in this case "on" is used to explain the time of year. Furthermore, Barack Obama realizing an error of the word, he corrects the wrong word to be the right word. It is appropriate with thoughts about transpositions by Fromkin (1971), he stated that transposition involves two units of speech production which replace the origin unit should be uttered.

The fourth type is substitutions. Based on the analysis, there are sixth data which classified as substitutions type. The substitutions type appeared in this research because Barack Obama uttered the word, which he replaced by the other word, but the original word that appears in unknown. This type occurs in five data $(7,8,10,11$, and 12). Obama wants to say "it has always" but the result of his uttered is " it is", in this case, he replaces the word "has" to be the word "is" (datum 7). The next, datum eight which, Barack Obama wants to say "it has always" but the result of his uttered is " it is", in this case, he replaces the word "has" to be the word "is"(datum 8). Then he wants to say the word "but" but the result of his uttered is "well", a slip of this datum he replaces the word "but" to be the word "well" (datum 10).

Further, datum eleven which, Barack Obama wants to say "The United States is unique" but the result of his uttered is "The United States has unique", he replace the word "has" to be the word "is" (datum 11). And the next, datum twelve which, Barack Obama wants to say "and " however the result of his uttered is " but", he unintentionally made an error in his uttered; there is he put the word but which should be and. Substitutions occur as Obama pronounces a word or sound, and replaces it with another unit, and the source word that uttered is unknown. It is appropriate with thoughts about transpositions by Fromkin (1971), he stated that substitution occurs when the word is replaced by the other word, but the original word that appears in unknown.

The next type is a counter blend, according to Fromkin (1971), the counter blend is almost the same with a blend which combines two words or sentences. However in the counter blends is 
someone produces a blend, then at the second attempt to create the intended speech, resulting in the second blend using elements remaining from the first blend. In other words, the counter blend is the phenomenon of blending in the second time; in this case, the speaker combining or blending twice from several words. In this study, the counter blend is not found. As the speaker always corrects the word to utter.

The sixth type is haplologies; in this study, there are two data which classified as haplologies type. The haplologies type occurred in this research because Barack Obama uttered the sentences then he requires to skip part of the target utterance. The datum 4 and datum 12 contain haplologies type. In datum 4, Obama uttered the sentence "So so you just have to -- you have to get back" In the first utterance the speaker utters the letter of "just", furthermore in the next sentence of the speaker skip these word. In this case, the speaker skipping the word of just.

Further, in datum 12, Barack Obama uttered the sentence "when we were - when were campaigning" From this utterance, Obama requires to skip part of the target utterance. In the first utterance, the speaker utters the letter of "we", furthermore he correct his sentence. However, he skips the word "we". In this case, he should use the pronoun "we", it shows plural, refers to Obama and Michelle. Finding of haplologies in this studies is appropriate with thoughts about haplologies by Fromkin (1971), he stated that haplologies occurrence the speaker require to skip part of the target pronounce.

The finding in this study obtains the pattern of slips of the tongue in political discourse that involves pauses because of respiratory and hesitation, repetition and some speech errors that happened in the phonetic, syllables, and word. It is also similar to those produced by non-native speakers (Asyura, 2017) and involving more on the phonological segment (Frisch and Wright, 2002). Such slips happen as deviations in speech errors in the planning processes specifying the targets of articulation and articulatory processes specifying the motor movements that execute the utterance plan (Goldrik et al., 2016). It results in the practice of content shifts on locus attention during speech production planning (Kawachi, 2002).

Slips of tongue in the context of native speaker's language production is related to several aspects, one of which is the phonological structures of the first language (Han et al., 2019). Substitution becomes the dominant type of slips of tongue occurring in the first language (AlBuainain, 2018) and also in a foreign language (Naibaho, 2018). Substitution not only occurs in adult speech but also in the slips of tongue produced in children's casual speech (Syukri, 2018) and even in the utterance of very young children when speaking to their mother and teachers (Warren, 1986). The difference in the type of substitution concerns with the speaker's language mastery. For beginner second language learners, the substitution occurs in deletion slips (Livia, 2016). In addition, native speaker's slips of the tongue do not cover the influence of the trigger in the context of the second language such as language transfer, language transfer learning, second language learning strategies and communication strategy (Suryadi, 2011).

Three factors influence an occurring slip of the tongue based on Clark and Clark (1977) theory, that are also found in this study, namely cognitive difficulty, situational anxiety, and social factors. The first factor is the cognitive difficulty, in the finding of this study showed that there are seven data of a slip of the tongue that categorized by the researcher that the cognitive difficulty. Some data categorized difficult cognitive. Datum 1. "You know, it didn't always manifest itself in the day to day grind of governing, but the truth is it's -- it never died out". In this section, Barack Obama tells about his successes when he was selected as president, it was not only from his struggle but the support of the people around him was one of his spirits. In the beginning, Barack Obama told about his experience smoothly and clearly, but in the middle, he spoke there was some silent pause, that is causes he hesitates to choose the word that will be 
uttered, that is causes the researcher categorized this datum as cognitive difficulty. Another datum that the use of cognitive difficulty is datum 3,9,10,11, and 12. Barack Obama got difficulty in choosing the right word to be uttered, although his speech is done quickly and showed some word repetition. Therefore it caused an unintentional error in his utterance.

The second factor is situational anxiety from the data analysis of this study shown that there are three data of a slip of the tongue that categorized by the researcher that situational anxiety. Some data belong to difficult cognition to recall a word like in the datum 5, "they're -- they haven't quite gotten to prime age". The context of both of them is when Barack Obama talked about his not being active in the political world as he was preoccupied with writing his first book, besides that he made an organization which aimed to build the next generation, organizers, journalists, politicians. A further example is in datum 7, "when you don't have -when you have at least one party". In this section, when Barack Obama answered the question from David Axelrod. His question is what Obama knows about President Trump, which is about what he will face and how he should be. The beginning of these sentences, Barack Obama speak with hesitation and repeating the word, besides he also very careful when he wants to say the word or sentence.

The third factor is a social factor, as found in three data of a slip of the tongue. There are the data that classified as an occurring slip of the tongue by social factor. Datum 2, "I -- I've -- I'm proud that I had tried to conduct myself in the office to do what I think is right rather than what is popular" In this section Barack Obama tells David and also audiences, about when he went to LA for the Democratic Meeting. In this case, categorized as a social factor because a slip of the tongue occurs as the reason Barack Obama is excited to tell about when he went to LA for the Democratic Meeting, to the David and audience. The atmosphere of the speaker will affect the utterance that produced when Barack Obama is excited about the topic he does not attend to his pronouncement.

Another datum use of social factor is datum 6 which Obama said, "It is - it has always been the fault line" The context of this sentence is when Obama responds to David Axelrod's statement that why America is a bluer and redder today than ever and is at the core of some of that. In this case Barack Obama such as pressured by the question raised by David Axelrod, because when Obama will answering the question, he is like thinking what the sentences to say, this is known as it took longer to compile the sentence. Therefore the researcher categorized this datum as a social factor as an occurring slip of the tongue.

Slips of the tongue resulted from various aspects such as cognitive difficulty, situational anxiety, and social factors identify how cooperation and intention in conversation are in a highly complex interaction. It comes together with some substantial elements of individual traits, for instance, attention, private experience, and others (Gil, 2019). These aspects are similar in the context of first and second language (Kafifah et al., 2016).

The slips of tongue produced by a native speaker in political discourse show the practical implementation of the point of view of cognitive science which is interested both in how language is represented and also in how it is used. The occuring slips reflect linguistic units employed in particular speech, which are highly rule-governed and reflect the complex processes of the language production system that generates utterances (Bencini, 2017). Moreover, in the context of the interview as impromptu speech, slips of tongue may occur with some variations of repetition and hesitation (Hutabarat, 2015).

Knowing that even a native speaker cannot always avoid the trigger or factors supporting the occurrence of slips of tongue brings some implications to second language teachers. Teachers can model how to eliminate the occurrence of slips of the tongue as a variation of speech error 
by looking at the possible intervening factors in speech production. While in speech planning, the teacher can propose a general strategy such as using interjection or effective repetition. Some other technique is lengthening, inserting filler or pause (Braun and Rosin, 2015).

Regarding slips of the tongue made by learners or children, studies propose that teachers should consider them as part of language acquisition (Ovchinnikova, 2007; Syukri, 2018). Slips also tend to occur in the context of bilinguals, especially when the first and second language have similar spelling patterns and rules (Zheng, 2006). Whereas for beginner second language learners are supposed to do more practice to automatize their speech production to eliminate the occurrence of slips of the tongue. Accordingly, they can apply vaious effective communication strategies (Panggabean and Wardhono, 2017). However, slips of the tongue is a natural phenomenon in speech as it becomes 'windows to the mind' showing the level of cognitive control, and end up as verbal mirrors of thoughts and emotions (Rădulescu, 2011).

\section{CONCLUSION}

Based on the analysis, the slip of the tongue occurs in Barack Obama interview at The Axe File are anticipation, perseveration, transposition, substitution, blend, and haplologies. The type of slip of the tongue that was not found by the researcher is a counter blend. The dominant type that occurs in in Barack Obama interview is a substitution. The substitution involves syllables and words as a result of the practice of content shifts on locus attention during speech production planning. In addition, the factors influence which makes Barack Obama produces slip of the tongue are a cognitive difficulty, situational anxiety, and social factors.

This study only takes the data of the conversation in the interview that posted on the Youtube. Future research should examine a slip of the tongue in other contexts, such as in a direct conversation to find any similarity or difference. As the implication of this study, second language teachers can encourage students to speak fluently without worrying of making an error as one of the finding showed that speaker of first or second language could produce similar pattern and cause of slips of the tongue.

\section{REFERENCES}

Aitchison, Jean. (2008) The Articulate Mammal an Introduction to Psycholinguistic. (5 ${ }^{\text {th }}$ ed). New York: Routledge

Al-Buainain, H. (2018). Slips of the tongue: Examples from Qatari Dialect. In Qatar Foundation Annual Research Conference Proceedings Volume 4(4),Hamad bin Khalifa University Press.

Altiparmak, A \& Karuoglu, G. (2014). Slips of the Tongue: A Psycholinguistic Study in the Turkish Language. Humanities and Social Sciences Review 2(3), 241-254.

Asyura, A. (2017). Pause and Slip of the Tongue on Stand-Up Comedy Show in Indonesia. Proceedings of INTCESS 2017 4th International Conference on Education and Social Sciences 6-8 February, Istanbul, Turkey.

Bencini, G. M. (2017). Speech Errors as a Window on Language and Thought: A Cognitive Science Perspective. Altre Modernità, 243-262. doi:10.13130/2035-7680/8316

Boomer, D. S., \& Laver, J. D. (1968). Slips of the tongue. British Journal of Disorders of Communication, 3(1), 2-12.

Braun, A., \& Rosin, A. (2015, August). On the speaker specificity of hesitation markers. In $I C P h S$.

Clark, H. I and Clark, E.V. (1977) Psychology, and Language. An Introduction Psycholinguistics. New York: Harcourt Brace Jovanovich, Publishers. 
Dell, G, S., and Reich, P, A. (1986). Stages in Sentence Production: An Analysis of Speech Data. Canada: Journal of Verbal Learning and Verbal Behavior, 20(1), 611-629. doi=10.1037\%2F0033-295X.93.3.283

Dentrianto, B. (2017). Slip of the Tongue in English Classroom Presentation Thai and Libyan at English Language Letters Department. 5th Asian Academic Society International Conference, "Multidisciplinary Perspective of Local Wisdom: Past, Present, and Future of Asia", pp. 112-120.

Fitriana, M. (2018). Slip of the Tongue in Interview Production of Indonesia State Officials: A Psycholinguistic Study. International Journal of English Literature and Social Sciences, 3 (4), 536-540. doi:10.22161/ijels.3.4.10

Frisch, L \& Wright, R. (2002). The Phonetics of Phonological Speech Errors: An Acoustic Analysis of Slips of the Tongue. Journal of Phonetics, 30 (1), 139-162. doi: 10.1006/jpho.2002.0176

Fromkin, V., (2006). Interview Error as Linguistics Evidence. Paris: Mouton.

Gil, J. M. (2019). A relational account of communication on the basis of slips of the tongue. Intercultural Pragmatics, 16(2), 153-183. doi:10.1515/ip-2019-0008

Gleason, J. B., \& Ratner, N. B. (1998). Psycholinguistics. Fort Worth: Harcourt Brace College Publisher.

Goldrik, M., Keshet, J., Gustafon, E., Heller, J., \& Needle, J. (2016). Automatic Analysis of Slip of the Tongue: Insights into contive Arthitecture of Speech Production. Cognition 149(1), 31-39. doi: 10.1016/j.cognition.2016.01.002

Han, J. I., Oh, J., \& Kim, J. Y. (2019). Slips of the tongue in the Seoul Korean Corpus of spontaneous speech. Lingua, 220, 31-42. doi: 10.1016/j.lingua.2019.01.001

Harley, T.A. (2001). The Psychology of Language. (2th ed). Hove: Psychology Press

Harley, T.A. (2006). Speech errors: Psycholinguistic approach. Invited entry in K. Brown (Ed.), The Encyclopedia of Language and Linguistics (2nd ed., Vol. 11: pp. 739-744), Oxford: Elsevier.

Hutabarat, M. A. (2015). Repetition and Hesitation in Delivering Impromptu Speech (Doctoral dissertation, Universitas Negeri Medan).

Jeager. Jeri G. (2005). Kid's Slips: What Young Children's Slip of the Tongue, Reveal about Language Development. New Jersey: Lawrence Erlbaum.

Kafifah, N., Fauziati, E., Hum, M., \& Hikmat, M. H. (2016). Comparative Error Analysis on Spoken Production Made by Students of the Second and the Fourth Semester of English Education Department of Muhammadiyah University of Surakarta (Doctoral dissertation, Universitas Muhammadiyah Surakarta).

Kawachi, Kazuhiro. (2002). Practice Effects on Speech Production Planning: Evidence from Slips of the Tongue in Spontaneous vs. Preplanned Speech in Japanese. Journal of Psycholinguistic Research, 31(4), 363-390. doi: 10.1023/A:1019569724949

Livia, M. (2016). Freshmen's Slips of The Tongue in Esp Speaking Class of English Department at University of Muhammadiyah Malang (Doctoral Dissertation, University of Muhammadiyah Malang).

MacKay, D. G. (1970). Spoonerisms: The structure of errors in the serial order of speech. Neuropsychologia, 8(3), 323-350.

Motley, M. T., \& Baars, B. J. (1976). Semantic bias effects on the outcomes of verbal slips. Cognition, 4(2), 177-187.

Naibaho, T. A. S., Aziz, M., \& Sembiring, B. (2018). Slips of The Tongue Made by The English Study Program Students. Journal of English Education and Teaching, 2(4).

Ovchinnikova, I. (2007). Slips of the tongue in children's narratives: Connectionist interpretation. Psychology of Language and Communication, 11(1), 23-41. 
Panggabean, C. I., \& Wardhono, A. (2017). Communication strategies used by EFL students in their presentation. Indonesian EFL Journal: Journal of ELT, Linguistics, and Literature, 3(2), 39-54.

Poulisse, N, (1999). Slip of the Tongue. Philadephia: Jhon Benjamins Publishing Company.

Rădulescu, A. (2011). 'Slips of The Tongue'-A Psycholinguistic Approach. Economics, Management, and Financial Markets, 6(2), 768-772.

Suryadi, M (2011) Pergeseran Penempatan Leksikal Dasar Dalam Deret Sintagmatik Pada Tuturan Jawa Pesisir. In: International Seminar Language Maintenance and Shift. ISSN: 2088-6799, Semarang: Universitas Diponegoro, 2 July.

Syukri, M.A. (2018). Slips of the Tongue Produced by Indonesian Children in Casual Conversation. Proceedings of the International Conference on Language Phenomena in Multimodal Communication (KLUA 2018), pp. 321-326. doi: 10.2991/klua-18.2018.48

Warren, H. (1986). Slips of the tongue in very young children. Journal of psycholinguistic research, 15(4), 309-344. doi:10.1007/BF01067677

Zheng, Q. (2006). Slips of the Tongue in Second Language Production. Sino-US English Teaching, 3(7), 71.

Zhu, Q \& Liu, B. (2018) A Study of Categorization and Causes of Speech Errors. Teacher Education and Curriculum Studies, 3(1), 1-5. doi: 10.11648/j.tecs.20180301. 